\title{
Blanking Clearance and Punch Velocity Effects on The Sheared Edge Characteristic in Micro-Blanking of Commercially Pure Copper Sheet
}

\author{
Didin Zakariya Lubis ${ }^{1, \text { a }}$, Ichsan Ristiawan ${ }^{2}$ \\ ${ }^{1}$ Mechanical Engineering Department,Engineering Faculty,Universitas Negeri Malang, Semarang \\ St.No.5 Malang, East Java, Indonesia \\ ${ }^{2}$ Mechanical Engineering Department, Akademi Teknik Soroako, Soemantri Brojonegoro St. No.1, Soroako, LuwuTimur, \\ South Sulawesi, Indonesia \\ *didin.zakariya.ft@um.ac.id
}

\begin{abstract}
This study aims to identify the influences between clearance and punch velocity on the part edge quality of blanked parts. Experiments have been conducted using material copper, punch-die clearance and punch velocity variations. In order to determine the reachable punch-die clearance and punch velocity required for blanking. The quality of the part-edge characteristics shows that higher punch velocity and decreases clearance value can improve the part-edge quality, resulting in smaller burr height and rollover, and a larger shear zone. Furthermore, it could be observed that the part-edge quality improvement when blanking with high punch velocity is much more distinct for stele than for copper. According to blanking theory, this improvement was expected because copper have much higher heat conduction coefficients. Therefore, the heat dissipates faster and the desired stress relief effect does not take place to the same degree as for stele.

Copyright (C) 2017Journal of Mechanical Engineering Science and Technology All rights reserved
\end{abstract}

Keywords: Micro PunchClearance, Punch velocity, Copper.

\section{Introduction.}

Micro-components have been widely used in many industry clusters such as electronics, healthcare, aerospace, biomedicine and automobiles[1]. The miniaturization and weight reduction of various industrial products have become advanced, and higher accuracy and quality are strongly demanded for the parts needed for constructing these products [2].

One of the popular and highly-in-demand forming processes is shearing. Shearinghas been defined as a process employed in the manufacturing of metal parts with a specific design from sheetmetal stock and includes a wide variety of operations such as punching, blanking, embossing, bending, flanging and coining [3]. The process of micro-components is performed by not only shearing, but also by EDM, laser, and etching [4].

The blanking process has long been studied by several researchers for a wide variety of materials or workpieces as well as tool conditions to improve the quality of blanking products, especially the quality of the material surfaceon the micro-hole fabrication by mechanical punching process[5]. The accuracy of the machine from the blanking process is evaluated by the surface quality and dimension accuration. At the same time, the main factors that affect the quality of the blanked edge, according to [6], [7], [3] and [8] are clearance punch-die and punch velocity.

The high-volume production of micro-components should be the main goal for the design of micro-manufacturing [9].However, the blanking process is expected to be widely used, because of its high productivity and machining stability.This study discussesoptimization of clearance and the potential punch velocity as process parameters to influence product quality of tested material.

\section{Materials and methods.}

\section{A. Micro Punch CNC MachineTools}

One of the products developed is Micro Punch CNC Machine. Micro Punch CNC Machine is a combination of press dies machine with CNC (Computer Numerically Controlled) driving system as 
shown in figures 1 (a). Press dies can produce a part with uniform quality with minimum machining time. The working principle of press dies is using penetration between punch and $\mathrm{d}$

The alignment accuracy of punch and die Micro Punch CNC machine up to $10 \mu \mathrm{m}$ with the maximum force of $1663 \mathrm{~N}$. In addition, the blanking process on press dies system has several advantages, including it can produce a uniform sheared edge quality and size products with lower cost in the manufacturing of mass products.

\section{B. Materials}

The specimen used for the blanking process were strips of commercially pure copper sheet (99.6\%) with thickness of $500 \mu \mathrm{m}$. Punch tool using High Speed Steel (HSS) materials type Nachi Standard with a Rockwell C hardness of 64 HRC (figure 1 (b))while the die using Mild Steel (figure 1 (c)). Mechanical properties of experimental setupare shown in Table 1.

\section{Force Calculation}

The equation to measure the total force required to blanking the specimen(copper) with circular section is as follows.

$$
\mathrm{P}=\pi \mathrm{D} \mathrm{\tau}_{\mathrm{u}} \mathrm{t}
$$

Known that shear strength $\left(\tau_{w}\right)$ of the material is 0.7 times the tensile strength (TS) of $210 \mathrm{MPa}$. The obtained $\left(\tau_{w}\right)$ is $147 \mathrm{MPa}$. It can be obtained that the force $(P)$ needed to blanking the specimen with t: $500 \mu \mathrm{m}$ is $182.3 \mathrm{~N}$. Based on the calculation of the force required for punching process as compare to optimal punching machines, it can be concluded that the maximum force of $1663 \mathrm{~N}$ may allow blanking process on the specimenwith the required maximum force of $182.3 \mathrm{~N}$.

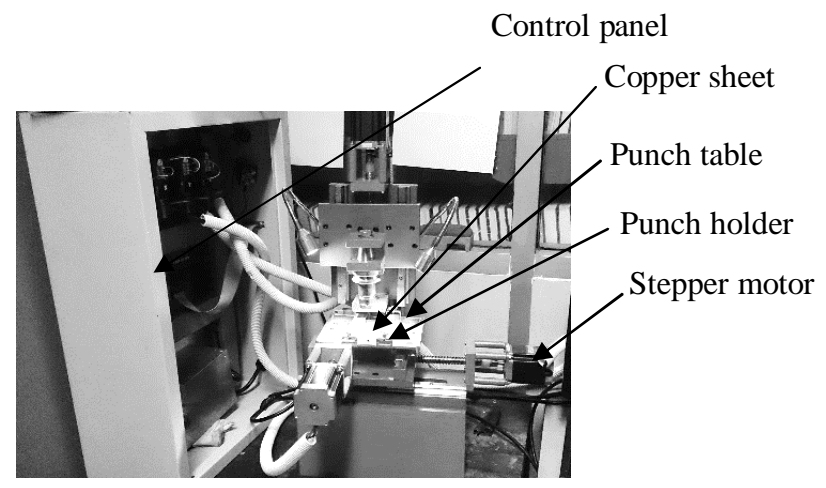

(a)

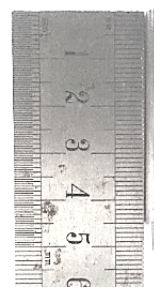

(b)

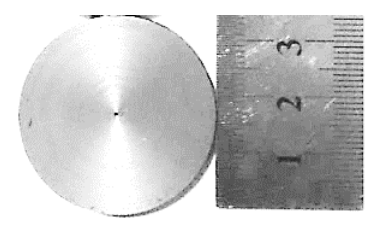

(c)

Fig. 1.(a)Micro Punch CNC Machine, (b) punch tool, (c) die

Table 1. Mechanical properties of experimental setup

\begin{tabular}{cccc}
\hline Properties & $\begin{array}{c}\text { Specimen } \\
\text { (Copper sheet) }\end{array}$ & $\begin{array}{c}\text { Punch tool } \\
\text { (High Speed Steel) }\end{array}$ & $\begin{array}{c}\text { Die } \\
\text { (Mild Steel) }\end{array}$ \\
\hline Young's Modulus (Mpa) & $118 \times 10^{3}$ & $207 \times 10^{3}$ & $220 \times 10^{3}$ \\
Poisson's Ratio & 0.34 & 0.27 & 0.28 \\
Density (kg/m ${ }^{3}$ ) & 8900 & 8138 & 7861 \\
Yield Strength (Mpa) & 33.3 & 3250 & 207 \\
Tensile Strength (Mpa) & 210 & 172 & 345 \\
\hline
\end{tabular}




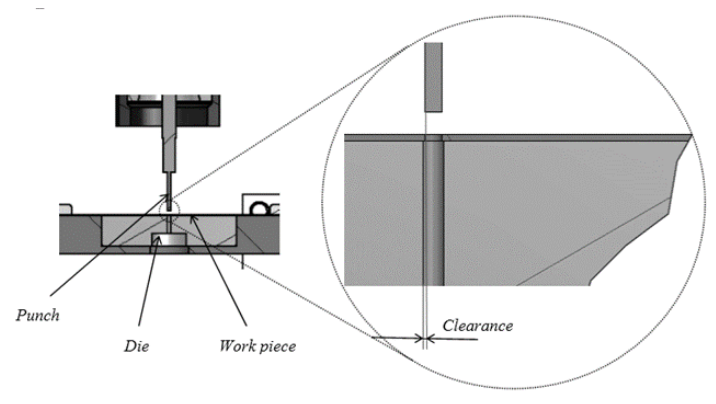

Fig. 2.Punch and die Clearance

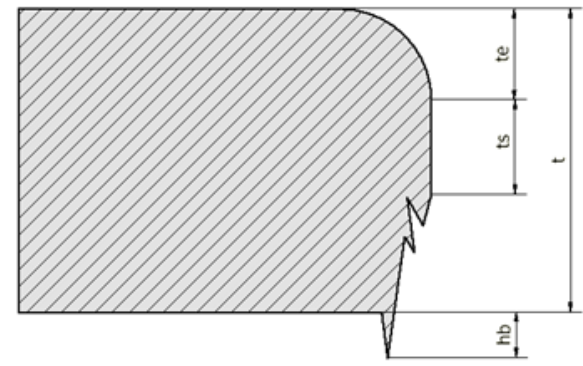

Fig. 3.Form errors on sheared specimen, t: sheet thickness,te: rollover, ts: shear zone and hb: burr height

Table 2. Variations in diameter punch against clearance

\begin{tabular}{ccc}
\hline Die Diameter $(\boldsymbol{\mu m})$ & Clearance & Various punch diameter $(\boldsymbol{\mu m}) \mathbf{t}=\mathbf{5 0 0} \boldsymbol{\mu m}$ \\
790 & $2.5 \%$ & 765 \\
& $5 \%$ & 740 \\
$7.5 \%$ & 715 \\
$10 \%$ & 690 \\
\hline
\end{tabular}

\section{Punch-die Clearance}

Clearances used for this study were 2.5, 5, 7.5 and 10\%. Figure 2 describes clearance punch and die used in this study.

The calculation of punch size variations based on the following formula.

$$
c=\frac{d_{d}-d_{p}}{2 t} \cdot 100 \%
$$

where $d_{p}$ is the external diameter of the punch, $d_{d}$ is the internal diameter of the die, and $t$ is the thickness of the specimen. The punch diameter variations result are shown in table 2 below.

\section{E. Testing Parameters and Measurement Method}

The experiment was conducted at room temperature.Punch velocity (v) of Micro Punch CNC Machine used 100, 500, 2000 and $2600 \mathrm{~mm} / \mathrm{min}$. In order to complete the accurate analysis of the blanking process there are performed four times to obtain the most valid data, and follow with clearance variation. The accuracy alignment measurement uses "Dino-Lite Edge AM 4515 T5" camera, featured with an LED light source that is located on the side of the punch serves as illumination during alignment process. The alignment between the punch and die is very important before doing the experiment, aimed to minimize the tool wear and to obtain a same sheared edge on the circumference of a circle.

The amount of shear zone from section of the slug were obtained using an optical microscope camera (Type Olympus C-35AD-4). To observe the validity of shear zones each slug has been measured at 5 different locations around the circumference (see figure 4).

\section{Results and discussion.}

Table 1 shows that shear zone increases according to the increasing of punch velocity and decreasing the clearance value. At the highest speed $(2600 \mathrm{~mm} / \mathrm{min})$ with the $2.5 \%$ clearance the shear zone up to $71.58 \%$. Consequently, the sheared surface is smoother and exhibits less burr formation.At low speed $(100 \mathrm{~mm} / \mathrm{min})$ with the same clearance value indicates shear zone value of $58.42 \%$. At the clearance value of $10 \%$ does not show the surface of the shear zone at all. 

Vol. 1, No. 2, November 2017, pp. 53-60

Table 3 . The shear zone results of the experimental measurement for commercially pure copper sheet

\begin{tabular}{ccccc}
\hline \multirow{2}{*}{ Clearance } & \multicolumn{4}{c}{ Shear Zone (\%) } \\
\cline { 2 - 5 } $2.5 \%$ & $\mathbf{1 0 0}(\mathbf{m m} / \mathbf{m i n})$ & $\mathbf{5 0 0}(\mathbf{m m} / \mathbf{m i n})$ & $\mathbf{2 0 0 0}(\mathbf{m m} / \mathbf{m i n})$ & $\mathbf{2 6 0 0}(\mathbf{m m} / \mathbf{m i n})$ \\
\cline { 2 - 5 } $5 \%$ & 58.42 & 59.47 & 64.21 & 71.58 \\
$7.5 \%$ & 19.47 & 25.79 & 44.74 & 48.42 \\
$10 \%$ & 0.00 & 0.00 & 0.00 & 4.74 \\
& 0.00 & 0.00 & 0.00 & 0.00 \\
\hline
\end{tabular}

Edge quality can be improved with increasing punch velocity, speeds may be as high as 2000 to $2600 \mathrm{~mm} / \mathrm{min}$. In Figure 4 (c), (d) sheared edges can undergo severe cold working due to the high shear strains involved.

(a)

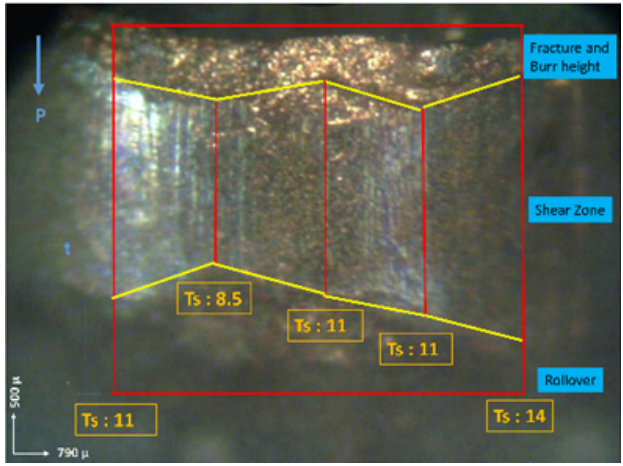

(b)

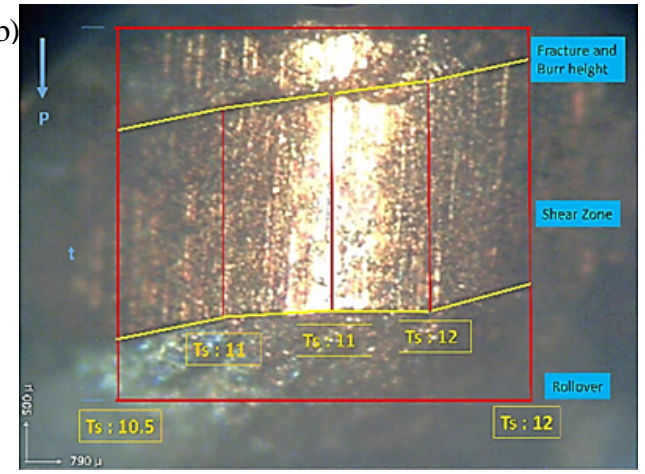

(c)

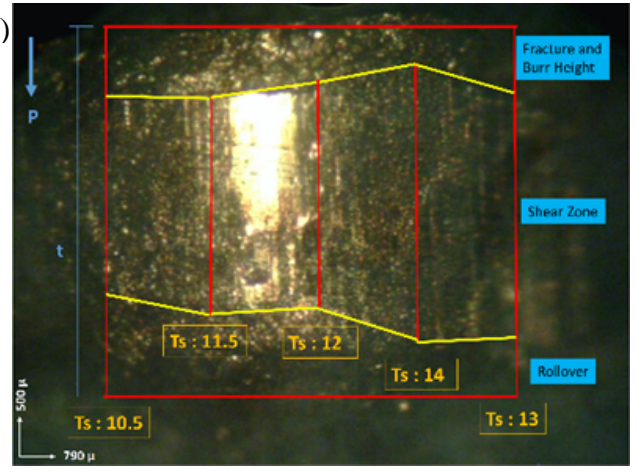

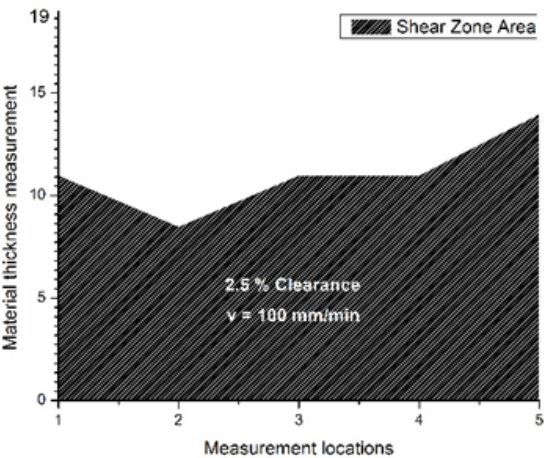
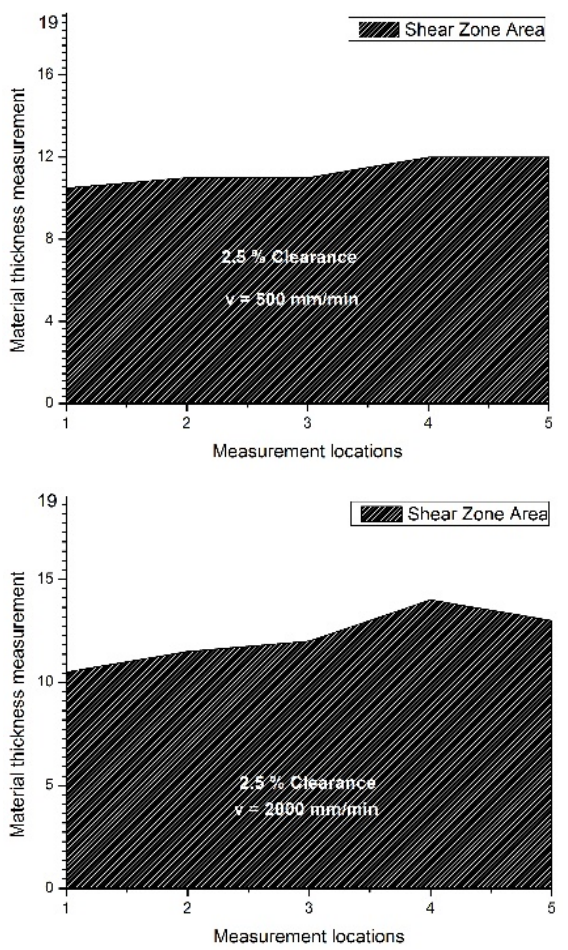
(d)

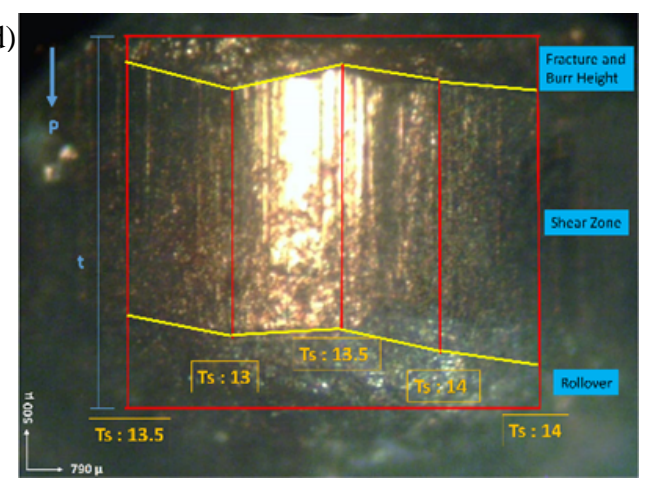

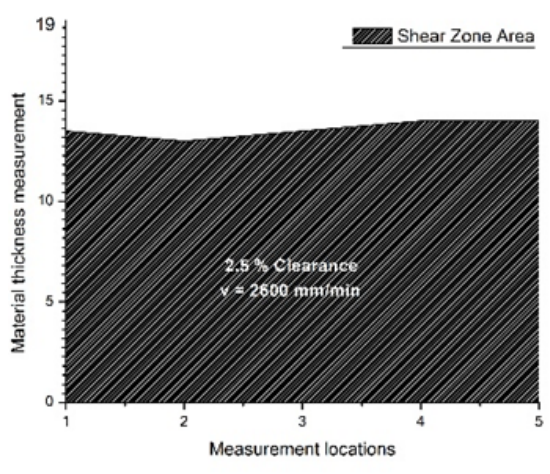

Fig. 4. Shear zone measurement result with deference punch velocity on $2.5 \%$ punch-die clearance using optical microscope camera, p: punch force, t: sheet thickness, v: punch velocity, ts: shear zone
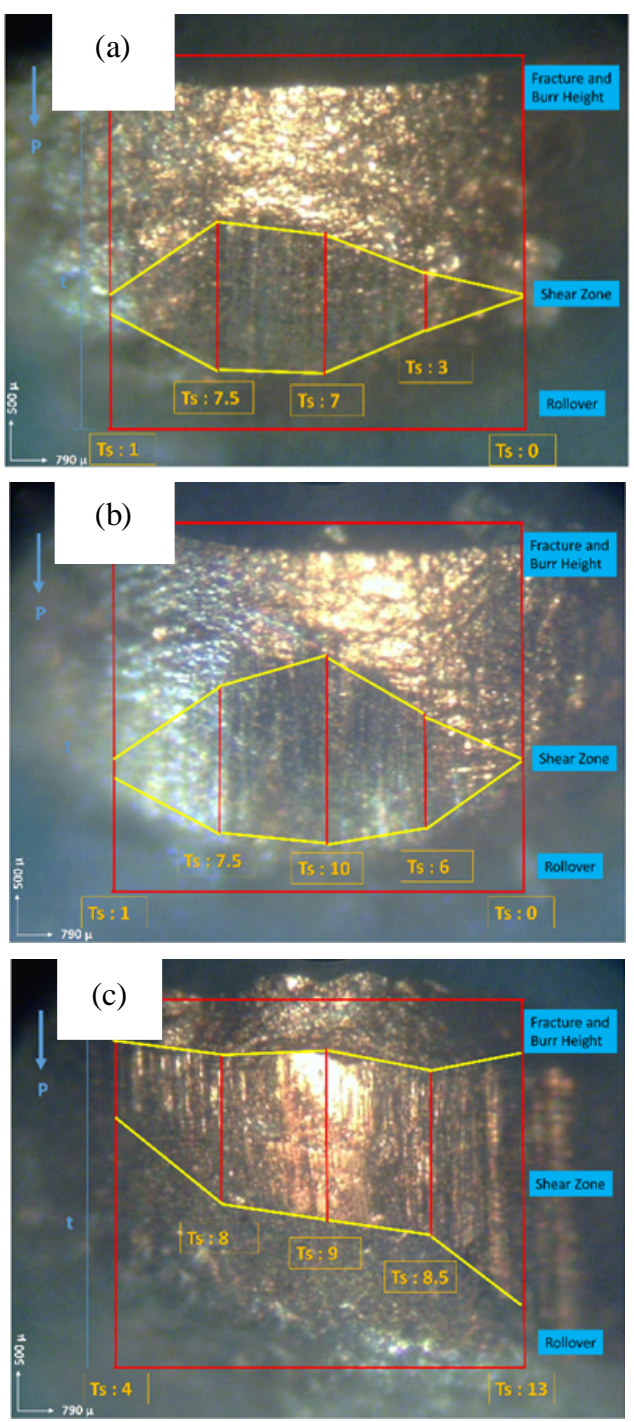
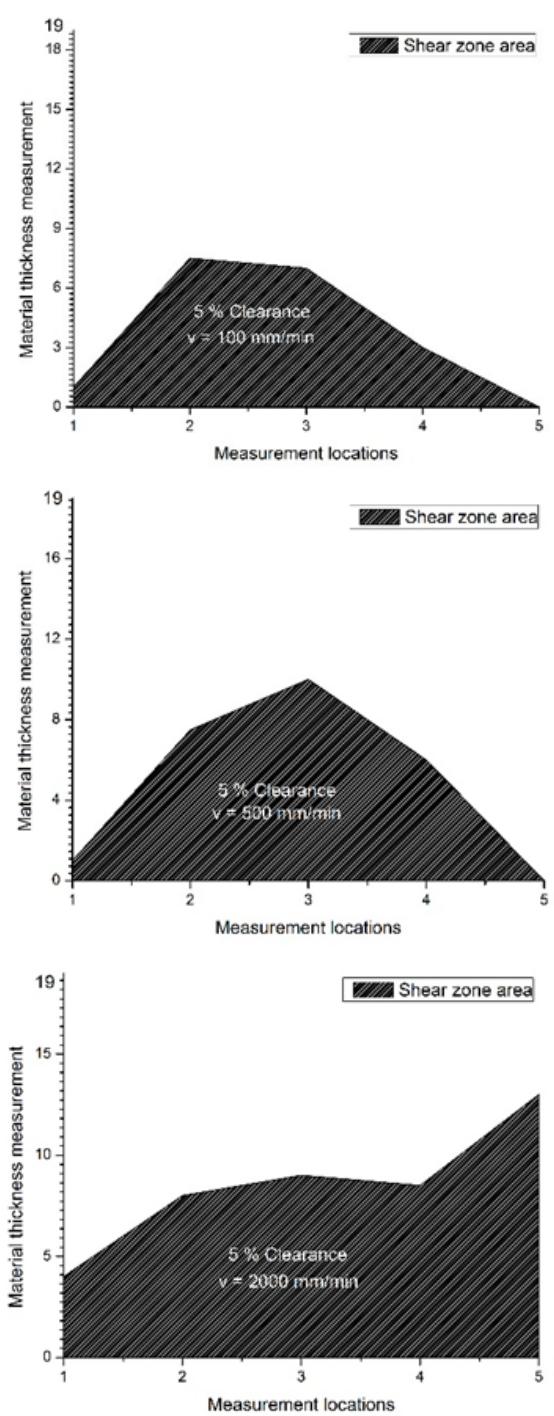

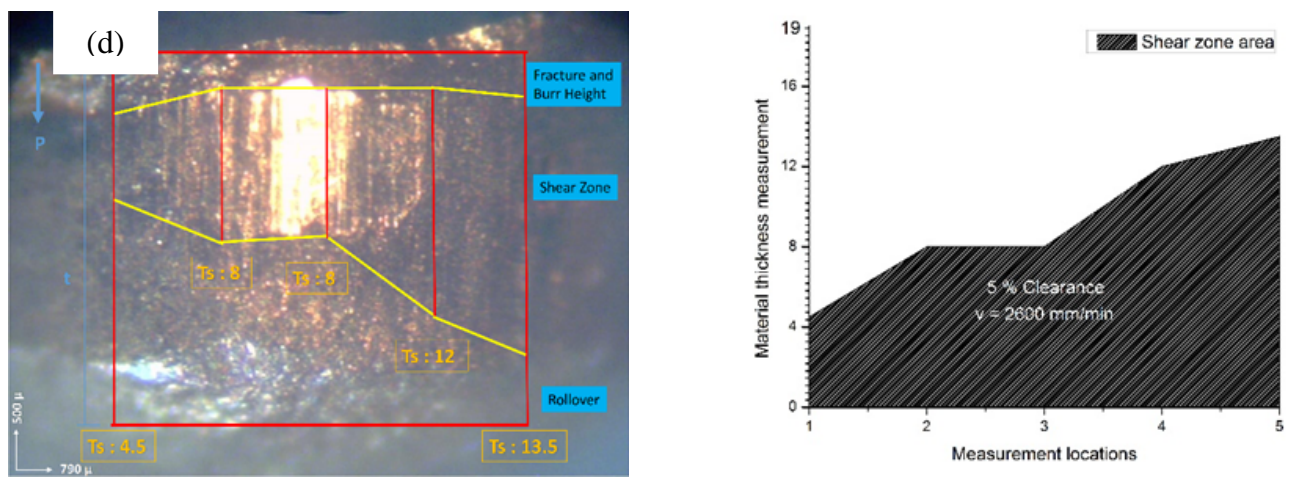

Fig. 5. Shear zone measurement result with deference punch velocity on $5 \%$ punch-die clearance using optical microscope camera, p: punch force, t: sheet thickness, v: punch velocity, ts: shear zone

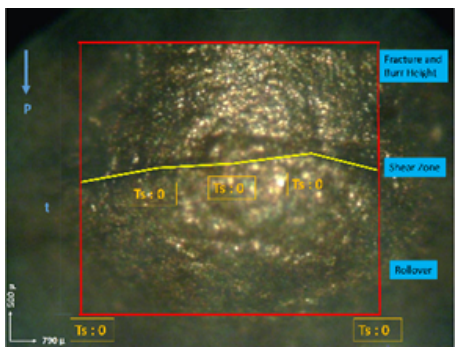

C: $7.5 \%, v: 100 \mathrm{~mm} / \mathrm{min}$

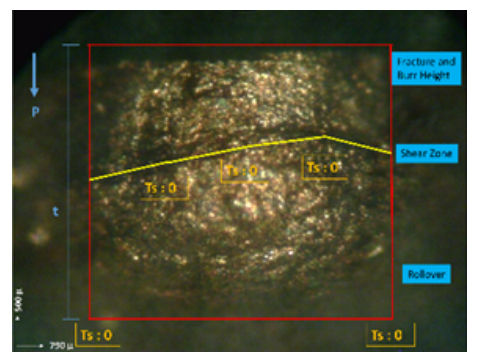

C: $7.5 \%, v: 500 \mathrm{~mm} / \mathrm{min}$

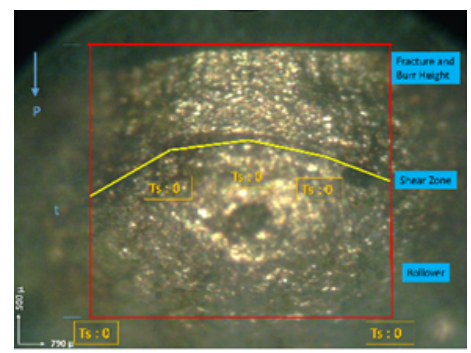

$\mathrm{C}: 7.5 \%, \mathrm{v}: 2000 \mathrm{~mm} / \mathrm{min}$
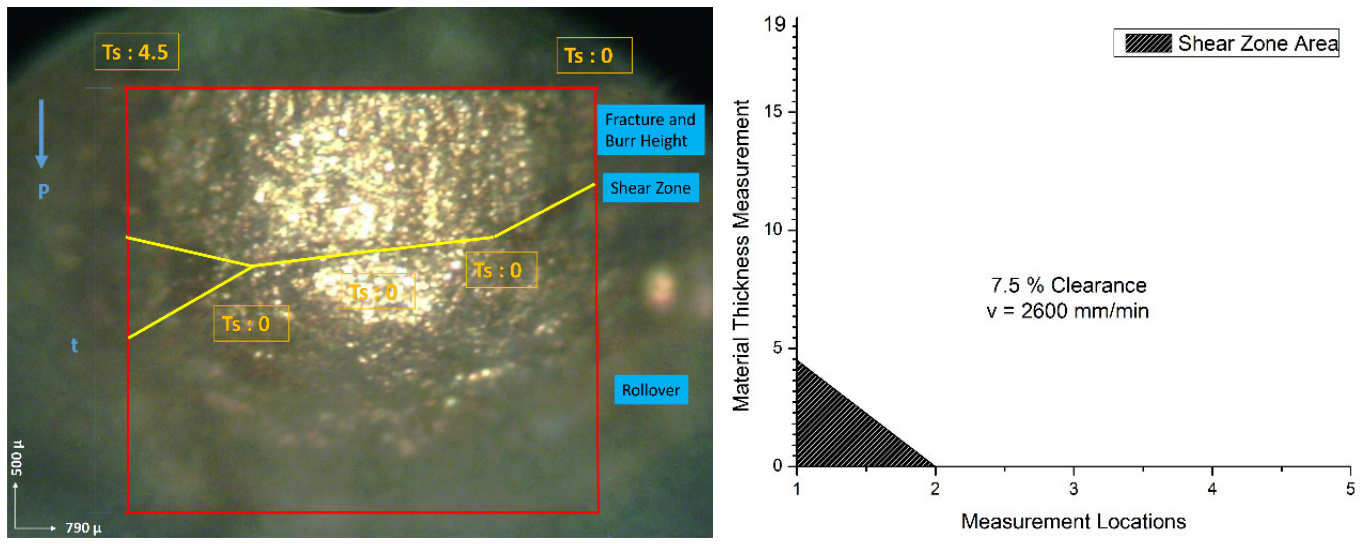

$\mathrm{C}: 7.5 \%, \mathrm{v}: 2600 \mathrm{~mm} / \mathrm{min}$

Fig. 6. Shear zone measurement result with deference punch velocity on $7.5 \%$ punch-die clearance using optical microscope camera, p: punch force, t: sheet thickness, v: punch velocity, ts: shear zone

Figure 5 shows at $5 \%$ clearance the surface of the shear zone has a proportion below $50 \%$. This is because the clearance value ratio is too large for copper sheet thickness of $500 \mu \mathrm{m}$, thuspart edge characteristic for the burr height and rollover will have a high enough proportion.

The study with clearance $7.5 \%$ (figure 6) was only 1 sample test at a speed of $2600 \mathrm{~mm} / \mathrm{min}$ which has a smooth surface, the other velocity samples do not show any sheared edge, the surface looks rough and dull.

It can be noted from figure 7 that the shear zone is null for $10 \%$ clearance in all punch velocity value. As the clearance value increases the zone of deformation becomes larger and the sheared edge becomes rougher. The sheet tends to be pulled into the clearance region, and the perimeter or edges of the shear zone become rougher. 


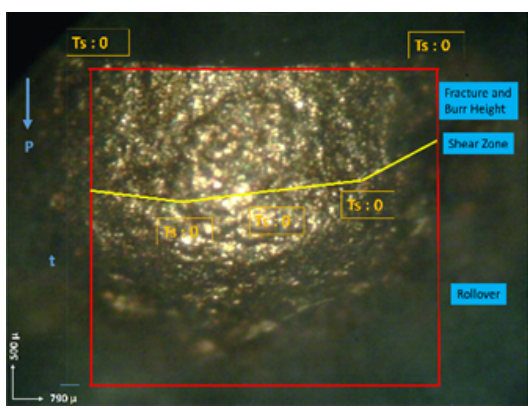

C: $10 \%, v: 100 \mathrm{~mm} / \mathrm{min}$

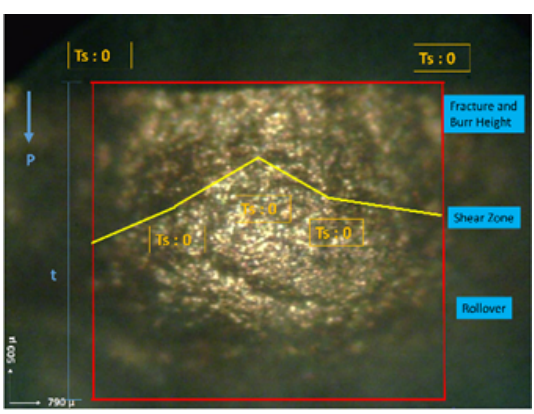

C: $10 \%, v: 2000 \mathrm{~mm} / \mathrm{min}$

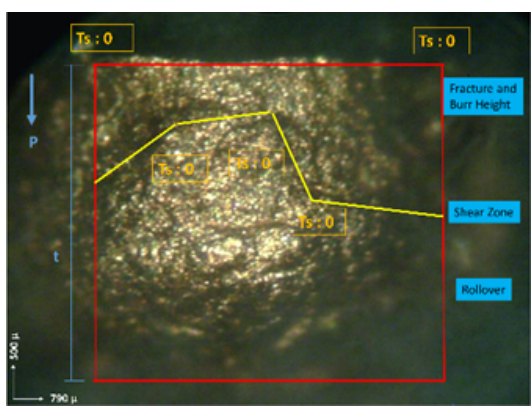

$\mathrm{C}: 10 \%, \mathrm{v}: 500 \mathrm{~mm} / \mathrm{min}$

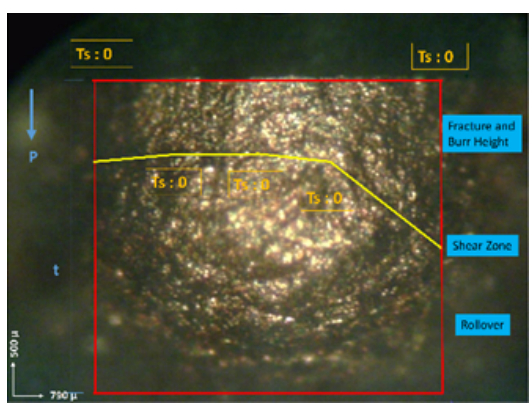

C: $10 \%, v: 2600 \mathrm{~mm} / \mathrm{min}$

Fig. 7. Shear zone measurement result with deference punch velocity on $10 \%$ punch-die clearance using optical microscope camera, p: punch force, t: sheet thickness, v: punch velocity, ts: shear zone

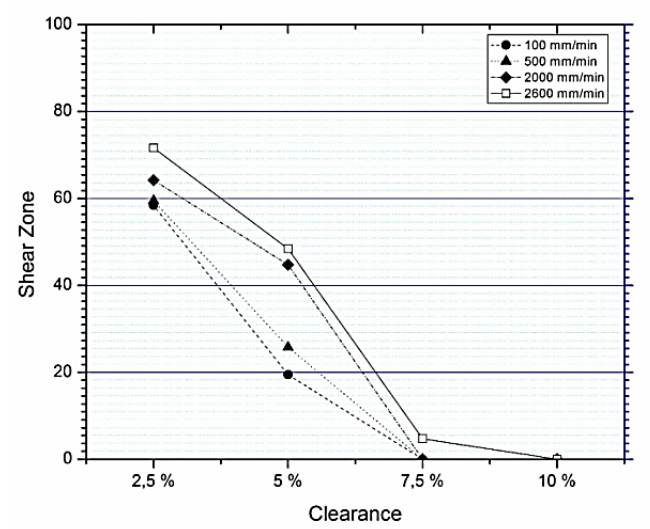

Fig. 8. Shear zone area with difference punch velocity against punch-die clearance

Figure 8 shows a comparison graph between clearance and shear zone at each punch velocity $(100,500,2000,2600 \mathrm{~mm} / \mathrm{min})$. The graph clearly shows that the highest punch velocity and the lowest clearance value produce the highest shear zone, and vice versa the lowest punch velocity with the highest clearance value yields a zero value.

This present Research conducted in accordance with research that has been done previously by [4], [10] and [11]increasing clearancevaluebetween punch-die has an effect: a) rollover increase; b); small shear zone; c) bigger ruptureand; d) increasing burr. With increased on clearance, the deformation area becomes larger and the shearing zone becomes rough. A rough shearing zone can be accepted as a product, but continued operation may be needed to make the blanked edge smoother, this may increase production costs. 


\section{Conclusion}

A good clearance design not only increasing the quality of product manufactured, but also reduces burr height. Influence clearance and potential punch velocity in this research showed good agreement with [4]. The ideal outcome of part-edge characteristics is having small rollover and burr and having at least $75 \%$ of shear zone. This can be achieved with clearance value of $2.5 \%$.

\section{Acknowledgments}

The authors would like to thank the DIKTI and Universitas Gadjah Mada for the support given to this research.

\section{References}

[1] T. Masuzawa, "State of the Art of Micromachining," Ann. te CIRP vol. 49/2/2000, vol. 49, no. 1, p. 473, 2000.

[2] J. Jeswiet et al., "CIRP Journal of Manufacturing Science and Technology Metal forming progress since 2000," vol. 1, pp. 2-17, 2008.

[3] S. R. Schmid, "MANUFACTURING ENGINEERING Illinois Institute of Technology".

[4] Y. Kibe, Y. Okada, and K. Mitsui, "Machining accuracy for shearing process of thin-sheet metals Development of initial tool position adjustment system," vol. 47, pp. 1728-1737, 2007.

[5] B. Joo, S. Rhim, and S. Oh, "Micro-hole fabrication by mechanical punching process," vol. 170, pp. 593-601, 2005.

[6] K. Lange, "Handbook of Metal Forming -Society of Manufacturing Engineers." McGraw-Hill Companies, 1985.

[7] S. Ivana, Handbook of Die Design Second Edition. McGraw-Hill Companies, 2006.

[8] H. Y. Chan and A. B. Abdullah, "Geometrical Defect in Precision Blanking / Punching: A Comprehensive Review on Burr Formation," vol. 8, no. 9, pp. 1139-1148, 2014.

[9] A. R. Razalia and Y. Qin, "A Review on Micro-manufacturing , Micro-forming and their Key Issues," Procedia Eng., vol. 53, pp. 665-672, 2013.

[10]Z. Tekiner, M. Nalbant, and H. Gürün, "An experimental study for the effect of different clearances on burr, smooth-sheared and blanking force on aluminium sheet metal," Mater. Des., vol. 27, no. 10, pp. 1134-1138, 2006.

[11]C. Husson, J. P. M. Correia, L. Daridon, and S. Ahzi, "Finite elements simulations of thin copper sheets blanking: Study of blanking parameters on sheared edge quality," J. Mater. Process. Technol., vol. 199, no. 1, pp. 74-83, 2008. 